\title{
POLARIZED EMISSION SPECTRA OF TRIVALENT EUROPIUM IN GADOLINIUM ALUMINIUM BORATE
}

\author{
A.A.F. LAGERWEY \\ Grote Steger 13, Eijgelshoven, The Netherlanas \\ and \\ G. BLASSE \\ Physical Laboratory, State University. Utrecht, The Netherlands
}

Received 18 November 1974

The ${ }^{5} \mathrm{D}_{0}-{ }^{7} \mathrm{~F}_{2}$ emission lines of $\mathrm{GdAl}_{3} \mathrm{~B}_{4} \mathrm{O}_{12}-\mathrm{Eu}^{3+}$ do not follow the selection rules for electrical dipole emission. This is interpreted as evidence for pseudoquadrupole transitions.

A number of years ago the emission spectrum of $\mathrm{Eu}^{3+}$ in the hexagonal linthanide aluminium borates $\mathrm{LnAl}_{3} \mathrm{~B}_{4} \mathrm{O}_{12}$ has been reported for powder samples [1]. The $\mathrm{Eu}^{3+}$ ion is surrounded by a trigonal prism of oxygen anions and its site symmetry is $D_{3}[2]$. The main emission consists of two ${ }^{5} D_{0}-{ }^{7} F_{1}$ and two ${ }^{5} \mathrm{D}_{0^{-}-{ }^{7}} \mathrm{~F}_{2}$ lines. In view of a suggestion made by Jgrgensen and Judd [3] that transitions with $\Delta J=$ \pm 2 may be pseudoquadrupole transitions and as such hypersensitive to their surnundings, it seemed interesting to study the polarization of these lines especially to see whether the ${ }^{5} \mathrm{D}_{0}-{ }^{7} \mathrm{~F}_{2}$ emission behaves as a (forced) electric dipole transition or not.

For this purpose we investigated $\mathrm{GdAl}_{3} \mathrm{~B}_{4} \mathrm{O}_{12}-$ $\mathrm{Eu}^{3+}(3 \%)$ crystals (size a few $\mathrm{mm}$ in all dimensions) with a very simple and inexpensive apparatus designed by one of us [4]. The excitation is with blue radiation. The measurements were performed at room temperature. The experimental results are given in table 1.

From these data it is clear that the ${ }^{5} D_{0}-{ }^{7} F_{1}$ emission is strongly polarized, whereas the ${ }^{-5} D_{0}-{ }^{7} F_{2}$ emission is not.

The ${ }^{5} \mathrm{D}_{0}-{ }^{7} \mathrm{~F}_{1}$ emission of $\mathrm{Eu}^{3+}$ is mainly magnetic dipole emission $[1,5]$. Under $\mathrm{D}_{3}$ symmetry the $J=1$ level splits into a doublet $A_{2}+E$, so that the polarization behaviour is not unexpected. The
Table 1

Emission spectrum of $\mathrm{GdAl}_{3} \mathrm{~B}_{4} \mathrm{O}_{12}-\mathrm{Eu}^{3+}$ (3ic) crystais

\begin{tabular}{|c|c|c|c|}
\hline Transition & $\begin{array}{l}\text { Peak } \\
\text { wavelength } \\
\text { (nm) }\end{array}$ & $\begin{array}{l}\text { Estimated } \\
\text { intensity } \\
\text { (linear) }\end{array}$ & Polarization 9 ) \\
\hline $\begin{array}{l}{ }^{5} \mathbf{D}_{0}-{ }^{7} F_{1} \\
\because\end{array}$ & $\begin{array}{l}59 i .7 \\
596.0\end{array}$ & $\begin{array}{l}4 \\
2 \\
1 \\
2.5\end{array}$ & $\begin{array}{l}1 \\
11 \\
1 \\
11\end{array}$ \\
\hline${ }^{5} \mathrm{D}_{0}-{ }^{7} \mathrm{~F}_{2}$ & $\begin{array}{l}613.6 \\
618.2\end{array}$ & $\begin{array}{c}9 \\
10 \\
4.5 \\
5\end{array}$ & $\begin{array}{l}1 \\
11 \\
1 \\
\text { II }\end{array}$ \\
\hline
\end{tabular}

a) The polnization characteristics of the radiation relative to the unique axis are expressed in terms of the plane of the electric vector.

$591.7 \mathrm{~nm}$ line is the transition to the $A_{2}$ component, the $596.0 \mathrm{~nm}$ line the one to the E component.

The ${ }^{5} \mathrm{D}_{0}-{ }^{7} \mathrm{~F}_{2}$ emission may be forced electric dipole emission [5] or pseudoquadrupole emission [3] The ${ }^{7} F_{2}$ siate splits into $A_{1}+2 E$ under $D_{3}$ symmetry. For dipole emission only the two transitions ${ }^{5} \mathrm{D}_{0}-{ }^{7} \mathrm{~F}_{2}(\mathrm{E})$ are expected with polarization $I$. Our experimental results contradict this expectation. 
For quadrupole emission, however, three emission lines are expected. In addition we expect also polarization for pure quadrupole transitions:

The only way out of this is to assume that the ${ }^{5} \mathrm{D}_{0}-{ }^{7} \mathrm{~F}_{2}$ transitions are pseudoquadrupole transitions. The five components of the electric quadrupole tensor are not necessarily equal to the five components at the europium nucleus, so that agreement for the polarization behaviour is rot required [3]. In addition one of the three possible ${ }^{5} \mathrm{D}_{0}-{ }^{7} \mathrm{~F}_{2}$ transitions must either have a low intensity or practically coincide with an other.

Finally we note that in other compounds the polarization behaviour of the ${ }^{5} \mathrm{D}_{0}-{ }^{7} \mathrm{~F}_{2}$ transition is as is to be expected for electric-dipole transitions ( $\mathrm{YPO}_{4}-\mathrm{Eu}$, $\mathrm{YVO}_{4}-\mathrm{Eu}$ [6]), but that in a scheelite mineral of Tecoripa, studied previously by one of us [4], the
${ }^{5} \mathrm{D}_{0}-\mathrm{T}_{1}$ emission is polarized as expected for magnetic dipcle emission; whereas the ${ }^{5} \mathrm{D}_{0}-{ }^{7} \mathrm{~F}_{2}$ emission shows no polarization in contradiction with the expectation for electric dipole emission.

\section{References}

[1] G. Bla:se, A. Bril and W.C. Nieuwpoort, J. Phys Chem Solids: 27 (1966) 1587

[2] A.D. Mills, Inorg. Chem. 1 (1962) 960.

[3] C.K. Jprgensen and B.R. Judd, Mol. Phys. 8 (1964) 281.

[4] A.A.F. Lagerwey, Thesis, State University Utrecht (1973).

[5] G.S. Ofelt, J. Chem. Phys. 37 (1962) S11.

[6] C. Brecher, H. Samelson, A. Lempicki, R. Rilcy and T. Peters; Phys. Rev. 155 (1967) 178;

C. Brecher, H. Samelson, R. Riley and A. Lempicki, J. Chein. Phys. 49 (1968) 3303. 